\title{
Sem Perdão
}

A lógica do perdão e da culpa, do esquecimento e da lembrança a partir de Freud

\section{No Forgiveness}

The logic of forgiveness, guilt, forgetfulness and remembrance according to Freud Daniel Omar Perez

\begin{abstract}
Resumo:O objetivo deste artigo é apresentar o paradoxo do ato do perdão e sua eventual impossibilidade. Para tal fim, apresentaremos primeiro o problema da relação entre a memória e o esquecimento. Num segundo momento, apresentamos o dispositivo freudiano da lembrança e o esquecimento. Finalmente, propomos que a relação com um evento lembrado do passado não pode ser perdoado, mas esquecido enquanto evento causa de dor e lembrado em outro sentido. Palavras chave: Perdão. Culpa. Freud.
\end{abstract}

\begin{abstract}
The aim of this paper is to present the paradox in the act of forgiving and its eventual impossibility. To do so, we will firstly present the problem of the relationship between memory and forgetfulness. We will then present the freudian device of memory and forgetfulness. Finally we propose that the relationship with a remembered event cannot be forgiven, but it may be forgotten as an event that causes pain and may be remembered in another manner. Key words: Forgiveness. Guilt. Freud.
\end{abstract}

\section{Esquecer e Lembrar ${ }^{1}$}

\section{A lembrança perfeita é uma eterna repetição do mesmo. Lembrar tudo, absolutamente tudo, não es- quecer nada, implicaria permane- cer no mesmo evento recapitulado}

indefinidamente. Uma máquina de lembrar tudo teria que arquivar até o último elemento e ao mesmo tempo lembrar a lembrança do já lembrado, tarefa sem fim. No acúmulo das informações do passado

\footnotetext{
${ }^{\star}$ Professor adjunto da Universidade Estadual de Campinas (UNICAMP)

${ }^{1}$ Este artigo faz parte de um debate iniciado em conversas na montanha com Antonio Edmilson Paschoal. No final da ditadura cívico-militar na Argentina (1976-1983), diante da iminência de um novo governo democrático, várias vozes de setores protagonistas e colaboradores do terrorismo de Estado procuraram implantar a ideia de esquecer e perdoar os atos de "excesso" cometidos no período de uma "guerra suja" com a justificativa de que isso nos permitiria a todos olhar para o futuro e não ficarmos amarrados ao passado em busca de vingança. Milhares de perseguidos, sequestrados, torturados, familiares de assassinados e desaparecidos e a sociedade civil no seu conjunto deveriam deixar para trás o ressentimento: esquecer e perdoar.
} 
até a retenção do detalhe último não há possibilidade de algo novo aparecer. A única possibilidade de sair da roda da lembrança seria deixar de ter uma lembrança detalhada de cada coisa e de cada momento passado: parar de lembrar o lembrado. Assim, poderíamos dizer que é preciso esquecer para viver uma vida rememorativa e ao mesmo tempo projetiva. Essa é a sensação que fica após a leitura de Funes el memorioso, o conto de Jorge Luis Borges. O personagem principal do relato lembra tudo, não esquece nada, e enlouquece, ou pior, fica imóvel.

Em outro lugar Jorge Luis Borges também afirma que é porque esqueço que leio. Alguns anos mais tarde, como se estivesse encadeado a uma combinação possível da linguagem, Roland Barthes disse exatamente o mesmo pensamento. Se lembrasse de todos os significados de cada uma das palavras de um texto e tentasse elaborar o sentido desse texto levando em consideração tudo o leque de significações numa lembrança perfeita, sem nada esquecer, seria muito difícil avançar na leitura, por não dizer humanamente impossível. Algo que lembra e relembra o tempo quilo que deixamos para trás sem
Assim, o esquecimento parece fazer parte da própria constituição do sentido do texto na leitura e da possibilidade de sentido na vida, ou pelo menos de algum tipo de sentido possível, surgido a partir dos elementos que foram deixados para trás. Por dizer de alguma maneira, o sentido futuro de uma vida e a possibilidade de leitura do texto se produziria em parte pelo vazio deixado no ato de esquecimento do passado.

Tudo se passa como se esquecimento e lembrança se articulassem ao ponto de um depender do outro e produzir como efeito o sentido do texto, da vida, da história passada e futura. Porém, podemos nos interrogar sobre o que é esquecido nesse jogo de articulações, o que se deixa para trás e o que é retomado na produção de sentido. Melhor dizendo: como é que algo é esquecido ou lembrado?

Assim, pressupomos que não se trata de uma mera escolha racional e consciente. Escolher esquecer não é propriamente esquecimento senão autoengano. Não estamos falando de autoengano, senão da- 
simulação, sem atenuantes.

Em Lembranças encobridoras, Freud (1899) apela para a nossa escassa memória dos atos passados e escreve:

"Se nos é possivel lembrar através de muito tempo determinado evento, vemos nesta aderência à nossa memória uma prova de que tal evento causou em nós, na sua época, uma profunda impressão. Ter esquecido algo importante nos surpreende ainda mais do que recordar algo aparentemente indiferente" (Freud, 1899, vol 2, 330).

Este fragmento parte da diferença entre o evento como registro de percepção sensível e o valor (simbólico ou imaginário ${ }^{2}$ ) desse evento para o sujeito desse registro de memória. Esta diferença de valor entre um evento que se destaca e outro que não se destaca, seja ele esquecido ou lembrado, é decisivo na vida do sujeito num momento posterior ao evento lembrado. Podemos dizer então que a lembrança está articulada, na sua importância, no seu valor simbólico ou imaginário, com aquilo que o sujeito vivencia no momento que lembra. No caso de Freud, trata-se da lembrança e do esquecimento de um individuo, de uma pessoa comum, mas poderíamos pensar também num sujeito coletivo, na história de um grupo. Isto é, a lembrança e o esquecimento operam no sujeito individual ou no sujeito coletivo como uma impressão da percepção e como com um valor imaginário ou simbólico. Em ambos os casos aquilo que se recorda ou se esquece não resulta de um modo aleatório como mero resto de uma situação de falta de atenção ou cansaço. De acordo com Freud e também com Nietzsche, existem diferentes maneiras, todas elas muito precisas, de deixar para trás ou de esquecer elementos que nos permitam produzir um sentido. Um deles pode ser caracterizado como um "esquecimento patológico", tal como conceitua Antonio Edmilson Paschoal (2014, 2016) a partir da sua leitura de Nietzsche: O "patológico" do esquecimento do evento passado estaria exatamente no modo de operar em relação com o sintoma presente. Assim, o esquecimento e a

\footnotetext{
${ }^{2}$ Aqui utilizamos as noções lacanianas que em sua articulação são a base do Fantasma. Ver Lacan, J. (196667) O Seminário 14, A lógica do fantasma.
} 
lembrança não só referem à falta de atenção do momento passado, também dizem respeito às condições atuais.

No livro "El perdón, virtude moral"3 editado pela Editora Anthropos se menciona a perseguição, $o$ genocídio e o crime nos casos da história dos judeus, cristãos, ETA, mas nada se fala de Franco. Pacto de La Mocloa como acontecimento coletivo parece ter apagado da memória o terrorismo de Estado de 50 anos de ditadura de Franco. Tudo se passa como se o relato do horror se fizer desde o esquecimento de um horror ainda mais próximo. O evento foi organizado pela cátedra Santo Tomas em Ávila. Esse texto faz pensar que quando falamos estamos fazendo isso desde o esquecimento, cada um de nós como sujeitos individuais ou coletivos fala, em alguma medida, desde o esquecimento de um horror mais próximo ainda.

"Assim, o histérico -escreve Freud- apresenta uma amnesia total ou parcial no que diz respeito daqueles eventos que tem provocado a sua doença, es- ria a origem do sintoma que pa- ses eventos, independentemente do seu conteúdo, tem adquirido (Freud, 1899, vol 2, 330).

No caso da histeria o esquecimento "patológico" do evento seria fundamental para a própria produção e manutenção do sintoma. É preciso apagar a lembrança do evento traumático para que o sintoma histérico apareça e se sustente. Por isso, para Freud, naquele período, era tão necessário lembrar para operar a cura. A consigna da psicanálise era tornar consciente $o$ inconsciente. Para os pacientes de Freud não bastava esquecer o evento para deixa-lo no passado. Aquele evento traumático esquecido operaria inconscientemente e estaria na base do mal-estar atual, portanto, devia ser lembrado ou tornado consciente para que o sintoma se dissolvesse. Esse era o princípio que legitimava o uso da hipnose. Em estado hipnótico, o paciente contava para o médico os acontecimentos que esquecia na vida consciente. Logo, o médico explicava para o paciente qual separa ele a máxima importância"

${ }^{3}$ Madina, E.; Mate,R.; Mayorga,J.; Rubio, M.; Zamora, J.A. El Perdón. Virtud moral. Em torno a Primo Levi. Madrid: Editorial Anthropos, 2011. 
decia. A lembrança, o reconhe- eventos neutros. Deste modo, pocimento consciente do ato deve- demos contar uma bela história ou ria permitir ao paciente se desfazer do sintoma e poder avançar sem aquele mal-estar na sua vida. A técnica teve uma eficácia bastante reduzida e Freud a abandonou. O problema não era apenas lembrar um fato como se se tomasse nota, como se se registrasse o evento num livro de contabilidade. Faltava ainda o que fazer com a lembrança. Faltava elaborar.

\section{Encobrir para não lembrar}

Outro dos mecanismos do esquecimento é o de substituir o evento de máxima importância esquecido por eventos indiferentes lembrados perfeitamente. As "lembranças encobridoras" de momentos irrelevantes reforçam o mecanismo do sintoma e da repetição do mesmo permitindo contar uma história sem conflitos e sem tensões ou pelo menos sem conflitos muito tensos que dificultariam a vida cotidiana no presente. Tudo funciona de modo tal que na história do sujeito, individual ou coletivo, aparecem lembranças de um relato mais ou menos entediante onde o nosso presente fica sem marcas traumáticas ou de conflitos do passado. Uma história de lembranças encobridoras desautoriza qualquer questionamento do sujeito com relação às suas tensões atuais e mantem o mal-estar do sintoma a resguardo da análise. Este tipo de discurso constituído por lembranças encobridoras opera como uma forma de não ter que se defrontar com aquilo que ainda continua se fazendo presente. O conflito permanece encoberto sem exame nem elaboração e aparece na forma de sintoma histérico como algo fora da série, que precisa ser medicado, cortado ou extraído. Em algumas análises freudianas a paciente conta e reconta a história da sua vida fragmentariamente várias vezes como se a articulação das palavras do seu discurso não pudessem dar conta daquilo que se passa com seu malestar atual, e de fato, não dá conta. A história de um grupo também é recontada pelos seus integrantes várias vezes em vários tempos diferentes. Em ambos os casos a história passada se narra desde o 
presente, quer dizer que o ponto sim, podemos dizer com Freud que de enunciação daquele que evoca aquilo que não se lembra então se reuma narrativa histórica individual pete. É preciso, portanto, lembrar e ou coletiva. Assim sendo, a narra- no seu significado incluímos elaboção está determinada por uma po- rar para não ficar detido na repesição de sujeito que está marcada tição do mesmo e no mal-estar do pelo modo em que esse sujeito lida sintoma.

com seu mal-estar, com suas tensões na atualidade, no tempo presente. Não só o esquecimento independe da vontade racional do sujeito, também a lembrança. Não lembramos o que queremos lembrar, mas aquilo que a determinação atual do sujeito permite. É o modo em como o sujeito está determinado pelo seu mal-estar atualmente que o passado será exposto na narrativa da história e se apagarão ou lembrarão os eventos em jogo.

\section{Esquecer e Repetir}

Com Freud então, podemos dizer que lembrar um evento como traumático não é apenas uma operação de atualização. O evento lembrado nos coloca, enquanto sujeitos, em posição de ter que nos defrontar com ele. Como dizia o poeta: e agora José? Como em uma encruzilhada o sujeito está diante de si como diferente. Reconhecese como fazendo parte do evento no qual ele próprio se encontra repetindo. O problema não é meramente moral. O sujeito tem de fazer algo com ele próprio como implicado no ato da repetição. Freud dá uma alerta para as possibilida-

Se, por um lado podemos dizer que nem tudo é necessário que seja lembrado e até justamente o caso seria o contrário, algo deve ser esquecido para produzir sentido sem mera repetição, por outro lado, há esquecimentos que são parte de o ato de lembrar pode indispor uma doença na qual o sujeito fica ainda mais o sujeito com os outros detido na repetição do mesmo. As- e com ele próprio. Num grupo, ou 
num casal, a revisão dos eventos da história, segundo seja o momento, pode ter como consequência a desalienação, o laço entre ambos pode ser desfeito. A lembrança, que estava esquecida porque era insuportável psiquicamente para ambos os sujeitos, agora aparece de um modo rude. Incomoda, perturba talvez mais do que o próprio sintoma com o qual às vezes nos conformamos na vida individual, amorosa ou grupal. O malestar pode ser agudizado ao ponto de romper o laço do sujeito e abandonar o grupo, o trabalho analítico ou a relação amorosa. Ficar amarrado ao mal-estar em troca de não recordar é a opção "patológica" do sujeito, individual ou coletivo, que decide recuar. $\mathrm{O}$ impasse diante do evento lembrado se transforma num espaço aberto. Aquilo que se recorda como dano e provoca malestar não cessa de insistir em aparecer. Dessa forma as histórias clínicas de Freud nos indicam que às vezes o sujeito entra em angustia.

\section{Perdoar e castigar}

$\mathrm{O}$ que fazer com aquilo que en- precisa aguardar até o final de sequanto dano ou trauma em rela- mana, pode se confessar a qualquer 
hora e receber o correspondente é além ou aquém de qualquer deperdão. O judaísmo e o cristia- terminação, pode perdoar o impernismo, com dispositivos diferentes, doável. Deus inclusive pode persão culturas do perdão.

O perdão, em sentido cristão, supõe o pecado ou a ofensa e compreende a conversão. $\mathrm{O}$ pecado ou a ofensa como ponto de partida é concebido como um estado negativo. Algo deve ter sido quebrado e o perdão seria o modo de reparar na conversão do pecador ou ofensor. O perdão sempre parte de Deus, ele é o único que pode perdoar com efeito real. Em Marcos 2, 7 podemos ler: "Quem pode perdoar pecados senão apenas Deus?". Mas o perdão implica o arrependimento do crente. ser entendida em dois sentidos: Não só o Deus dos cristãos, tam- 1. Como seguir a Jesus, no senbém o Deus de judeus exige o ar- tido radical de mudança de vida; rependimento. A culpa opera na 2 . Como reconciliação, no senbase, como condição de possibili- tido de uma reconciliação não só dade do arrependimento e do per- com Deus como ente supremo mas dão. Mas não devemos nos con- também entre os homens, como tefundir com um detalhe que não rapia de regeneração da criatura é menor: como Deus não está na comunidade. O perdão aqui subsumido no jogo de determina- apresenta o aspecto terapêutico do ções causais conscientes, inconsci- Evangelho. Assim, sentir-se perentes ou naturais ${ }^{4}$, senão que ele doado significa passar da culpa ao

\footnotetext{
${ }^{4}$ Para um estudo das determinações conscientes, naturais e inconscientes ver Perez 2015.

${ }^{5}$ Para um estudo da terapia e da cura nos referimos a Perez (org.) 2007.

${ }^{6}$ Precisamos aqui destacar a diferença entre troca e dom. Depois de Marcel Mauss (2003) muitos são os estudos nesse sentido. Podemos ver vários fenomenologos trabalhando nessa linha.
} 
dom $^{6}$ de Deus. Com esse dom re- vitima e a singularidade do ofencebido do perdão de Deus o cristão sor impedem uma equação de repassa à tarefa do perdão. É assim como perdoar seria então um exercício cristão.

Assim sendo, a troca aparece no jogo das exigências humanas, tanto no castigo quanto no perdão. A exigência de um castigo como contrapartida de uma ofensa tem dois elementos:

1. supõe um equilíbrio de origem que foi quebrado e,

2. implica uma correspondência, uma proporcionalidade entre o quebrado e a reparação por castigo.

A relação entre ofensa e castigo supõe a correspondência dano por dano como retribuição e correspondente reparação ${ }^{7}$. A vingança ou o castigo buscam um suposto equilíbrio perdido que se revela impossível. Como começar a contar os danos entre sérvios e croatas ou entre judeus e muçulmanos ou entre o personagem de Clint Eastwood e o dono do bar no filme Os Imperdoáveis? A troca de danos é sempre desproporcionada, nunca um dano é igual a outro. A singularidade da sultado zero. No filme O Poderoso Chefão II Marlon Brando se reúne com os outros chefes de família e após calcular e ver que com a vingança todos perdiam decide combinar que devem parar a guerra. Não há vingança que cure a morte do filho, mas também não se trata de um perdão.

\section{O perdão romperia a lógica da correspondência e das trocas e in- troduziria um dom?}

Se o meu perdão exige um arrependimento então se estabelece uma troca, isto é, um cálculo. No arrependimento há uma hierarquia moral explicitamente reconhecida e uma submissão àquela superioridade moral em função do reconhecimento, isto é uma clara relação de poder. Nesse casso, podemos dizer que o que temos é uma desculpa, uma anistia, um indulto, mas não propriamente perdão como dádiva. Não há qualquer gratuidade no gesto humano que exige arrependimento, como

\footnotetext{
${ }^{7}$ Ver a teoria da pena na Doutrina do Direito em Kant.
} 
não haveria nada parecido com um perdão se não houvesse o arrependido. Não faz sentido perdoar a quem não se reconhece perdoado por uma culpa. Um perdão sem contrapartida seria um ato solipsista. Do ato consciente da culpa se derivaria o ato consciente do arrependimento e a consequente concessão do perdão como desculpabilização.

Mas se aceitarmos com Freud que nem tudo é causado por representações mentais conscientes ou por necessidade biológica (isto é, que o ato não foi causado por uma escolha consciente ou por uma necessidade natural), e abrirmos o espaço para uma terceira causalidade: a causalidade psíquica inconsciente, então a situação se complica. Um evento considerado como causado por determinações que não são meramente conscientes não teria propriamente um responsável, um culpado com tudo o que isso implica senão o resultado de um ato não volitivo. Assim sendo, o registro inconsciente não sabe de volição e também não sabe de perdão. $\mathrm{Na}$ ordem do inconsciente não haveria a quem per- doar nem o que perdoar.

$\mathrm{Na}$ Psicopatologia da vida cotidiana Freud mostra que determinados atos seriam provocados pelo mecanismo da vida psíquica inconsciente, onde o individuo consciente não tem controle. Trocar o nome do esposo ou esposa pelo nome do ou da amante pode ser uma dessas situações que não tem perdão e nem desculpa, mas não pela valoração moral do ato senão porque o que está em jogo não é um ato consciente do individuo. De fato, ele não quis falar aquilo, mas falou. Mesmo que seja desculpável, a situação revela algo que não é da ordem da culpa ou da desculpa consciente. O sujeito que conscientemente pede perdão ou desculpa não é o mesmo que aquele que cometeu o ato.

$\mathrm{O}$ sujeito que realiza o ato não está posto lá apenas por uma escolha, há também um gozo que não controla. Lacan em vários Seminários tematiza essa noção de gozo, ou usufruto que toma o sujeito na sua posição ${ }^{8}$. Dito por outras palavras, se em um sentido há algo consciente no ato executado pelo sujeito, há ao mesmo tempo algo

\footnotetext{
${ }^{8}$ Ver especialmente O Seminário 7 e o 16. Para um estudo do gozo nos referimos a Braunstein 2007.
} 
que não se reduz a isso. Assim muitas. Nós poderíamos dizer que então perguntamos: alguém pode- Elaborar a lembrança neste caso ria pedir perdão e ser perdoado por é desmontar as condições de posum gozo no qual ele é tomado en- sibilidade da repetição do evento quanto sujeito? Alguém poderia como o mesmo e permitir apareperdoar um gozo? Parece difícil cer o novo. Isso é um trabalho, um responder afirmativamente já que exercício e não apenas um ato emonão parece haver conexão entre os elementos. Não há um tribunal da razão ou da consciência cuja jurisdição inclua a possibilidade de julgar o gozo sem cair na sua moralização arbitrária.

tivo. Em análise a elaboração requer um trabalho de corte e costura, para citar o Lacan de O Seminário 24 , onde a angustia, e portanto a incerteza, possibilita o ato e o reposicionamento simbólico do sujeito em relação com o gozo. Em situações histórico-políticas como

\section{Considerações finais: Lembrar e} Elaborar

Se o esquecimento do evento é patológico quando se trata de um evento que insiste em aparecer no presente na forma de sintoma, se a lembrança do evento nos conduz a um posicionamento com relação a ele, se a análise desse posicionamento nos revela a desproporcionalidade do castigo e o paradoxo do perdão, então o que fazer com os eventos traumáticos, com a tensão daquele traço do passado que ainda perturba?

A indicação de Freud é Elaborar. O texto Recordar, repetir, elaborar dá algumas indicações, mas não África do Sul e Argentina a elaboração se realiza por vias aparentemente opostas, num caso "a confissão e o perdão" no outro o "julgamento e a condena".

A elaboração do caso africano se realizou imediatamente depois da crise e a mudança de situação com relação ao Apartheid. A elaboração do caso argentino teve avanços e retrocessos até que 30 após a queda da ditadura podemos dizer que estamos em final de análise e aqueles que proponham esquecer e perdoar estão presos. Em ambos os casos a elaboração procura recompor a relação na comunidade mas não entre vitima e carrasco senão entre o sujeito coletivo do presente 
com sua própria história traumá- Edmilson Paschoal, não se trata de tica. Em nenhum dos casos se trata um querer para trás, mas de modos de reconciliação ou de vingança. de elaboração do que é esquecido Não se trata de reparar o irrepará- e do que é lembrado para que seja vel nem pela via do perdão, nem possível abrir o espaço onde algum pela via do castigo. Como disse sentido se apresente.

\section{Referências bibliográficas}

BORGES, J.L. Funes el memorioso. IN Obras Completas. Volume 1. Buenos Aires: EMECÉ.

BRAUNSTEIN, N. Gozo. São Paulo: Escuta, 2007.

LACAN, J. O Seminário 7 A ética da psicanálise. 1959-1960. Versão taquigrafada em língua original http://staferla.free.fr/S7/S7.htm O Seminário 7 A ética da psicanálise. 1959-1960. Rio de Janeiro: Jorge Zahar Editor, 1997.

O Seminário 14, A lógica do fantasma. (1966-1967) Versão taquigrafada em língua original http://staferla.free.fr/S14/S14.htm

O Seminário 16, De um Outro ao outro. 1968-1969. Versão taquigrafada em língua original http://staferla.free.fr/S16/S16.htm

O Seminário 16, De um Outro ao outro. 1968-1969. Rio de Janeiro: Jorge Zahar Editor, 2008.

FREUD, S. Los recuerdos encubridores. IN Obras Completas. Volume 2. Buenos Aires: 1988.

Psicopatologia da vida cotidiana. IN Obras Completas. Volume 4. Buenos Aires: 1988.

KANT, I. Princípios Metafísicos da Doutrina do Direito. São Paulo: Martins Fontes, 2014.

MADINA, E.; MATE,R.; MAYORGA,J.; RUBIO, M.; ZAMORA, J.A. El Perdón. Virtud moral. Em torno a Primo Levi. Madrid: Editorial Anthropos, 2011.

MAUSS, M. Sociologia e antropologia. São Paulo: Cosac Naify, 2003. 
PASCHOAL, A.E. Nietszche e o ressentimento. São Paulo: Editora Humanitas, 2014.

O ressentimento como inibição da ação, reação e ação na filosofia de Nietzsche. Revista de Filosofia Moderna e Contemporânea, v. 4, p. 34-43, 2016.

PEREZ, D.O. (org) Filósofos e terapeutas em torno da questão da cura. São Paulo: Escuta, 2007.

PEREZ, D.O. O Inconsciente, onde mora o desejo. Rio de Janeiro: Civilização Brasileira, 2015.

RUBIO, Miguel Perdonar al estilo y en nombre de Jesus. Sentido cristiano del perdón. IN El perdón, virtud politica. En torno a Primo Levi. Barcelona: Anthropos, 2008.

VÁRIOS AUTORES A Bíblia Sagrada. São Paulo: Sociedade Biblica Trinitaria, 2006.

Torá. São Paulo: Templo Israelita Brasileiro Ohel Yaacow, 2001. 
